\title{
Climate Change Impacts on Rainfall Distribution at Teluk Intan Catchment
}

\section{Zawani Mohd Zahudi ${ }^{1, a}$, Mohd Shalahuddin Adnan ${ }^{1, b}$, Nurul Farehah Amat ${ }^{1, c}$, Yuliarahmadila Erfen ${ }^{1, \mathrm{~d}}$ and Noorfathiah Che Ali ${ }^{1, \mathrm{e}}$}

\author{
${ }^{1}$ Department Of Water And Environmental Engineering, University Tun Hussein Onn Malaysia, \\ 86400 Parit Raja, Johor, Malaysia
}
awani6782@yahoo.com, bmohdshalahuddin@gmail.com, churulfarehahamat@gmail.com,

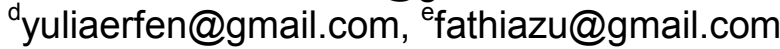

Keywords: climate change, drought, rainfall distribution, Teluk Intan

\begin{abstract}
Many studies have been conducted on determining the effect of climate change on the precipitation. The increasing of temperature has led to increase of evaporation rate, rainfall intensity, sea water level and so forth. These changes will lead to greater disaster such as increase of flood magnitude, flood event, drought intensity and prolong the drought period. The main objective of this study is to analyze the monthly rainfall pattern from 1984 to 1993 for the Teluk Intan Basin. Five stations of rainfall data were retrieved from DID. The rainfall distribution pattern was calculated by using two types of probability distributions known as Log-Pearson type-III and Gumbel using California's method. Later, Chi-square test of goodness of fit was applied to validate the results. Based on the calculated results, out of the five stations used in this study, only three stations shows are fitted to apply the mentioned method which is Mengkuang River St, Labu Kubong St and Telok Intan station. Maximum total rainfall for ten years period occurs at Pt. IV Sg. Manik St as the value is $5570.5 \mathrm{~mm}$, meanwhile minimum total rainfall occurs at Pt. I Sg. Manik St as the value is $1462.5 \mathrm{~mm}$. For the average temperature, year 1990 gives the maximum value that is $29.18^{\circ} \mathrm{C}$, while year 1986 gives the minimum value that is $28.79^{\circ} \mathrm{C}$. The chi-square test was performed to determine which method is fitted to use as statistical analyses. Lastly, correlation test was tested to determine the correlation between rainfall and temperature. Based on the correlation result, it clearly shows a weak correlation between rainfall and temperature. For Telok Intan St the correlation value is 0.17 , Pt. I Sg. Manik St is 0.28 , Mengkuang River St is 0.17 , Pt. IV Sg. Manik St is 0.4 , and lastly Labu Kubong St gives the smallest correlation value that is 0.07 . As a conclusion, the distributions of rainfall pattern in this area are not really affected by the temperature. However, the temperature distribution still will affect the rainfall distribution in a longer period.
\end{abstract}

\section{Introduction}

In recent years, climate change is one of the main issues that attracted the attention of researchers around the world. Measured temperature records of the earth have only been available since 1861 [8]. The earth's temperature before the instrumental period has been reconstructed using different indirect tools and methods like tree rings, corals, ice sheets, ice cores, borehole measurements, glaciers, ancient sediments and sea level changes etc [8]. The observed temperature record from 1861 to 2000 shows that the earth's temperature is increasing and most of the warming occurred during the second half of the twentieth century [8].

Increasing temperatures generally result in an increase in the water holding capacity of the atmosphere that leads to change in precipitation pattern and increase in atmospheric moisture [8]. Global land precipitation has increased by $2 \%$ since the beginning of the 20th century, but largely varied in space and time. Despite the irregularity in the trends of precipitation in the last century, the annual average precipitation in mid and high latitudes was increasing while that in tropics and sub-tropics was decreasing [8]. 
A number of researchers have managed to produce useful applications of extreme value distribution for rainfall data from several regions around the world. Examples Canada [12]; Greece [9]; India [7, 13]; Italy [2, 3, 4]; Jordan [5]. The only applications of extreme value distributions to rainfall data from Malaysia are the one that provided by Zalina et al [15]. Farago and Katz [6] have made a review of applications of extreme value distributions to climate data.

Based on the discussed problem, the main purpose of this paper is to determine the climate change impacts on rainfall distribution at Teluk Intan catchment. To achieve the purpose, rainfall and temperature data for five rainfall stations at Teluk Intan for ten years (1984-1993) were analyse. Then, the correlation test between rainfall and temperature data was done to determine wether both of the parameter are correlated or not.

\section{Materials and Methods}

Teluk Intan is located in the state of Perak in Malaysia with $4^{\circ} 2^{\prime} 0^{\prime \prime} \mathrm{N}$ latitude and $101^{\circ} 1^{\prime} 0^{\prime \prime} \mathrm{E}$ longitude. It is the largest town in Hilir Perak district and third largest town in the state of Perak with an estimated population of around 120,000 and estimated land size about $126.9 \mathrm{~km}^{2}$.

\section{Data collection and analysis}

The data consist of monthly maximum daily rainfall $(\mathrm{mm})$ records covering the period from January 1984 to December 1993 for the five locations at Teluk Intan (Teluk Intan, Labu Kubong, Stage I Sungai Manik, Stage IV Sungai Manik dan Sungai Mengkuang). The data were obtained from Drainage and Irrigation Department (DID) in Teluk Intan, Perak. Table 1 gives the latitude and the longitude of the five locations and some summary statistics of the corresponding data sets. Temperature data were extracted from the website of NAHRIM, which lists the daily and monthly temperature data for Teluk Intan region.

Probability and frequency analysis on the rainfall and temperature data were applied to determine the distribution of these data. Log-Pearson type-III and Gumbel distributions were selected to analyzed the distribution of rainfall and temperature in this study. For Log-Pearson typeIII distribution, the value of variate ' $\mathrm{X}$ ' (rainfall) is transformed to logarithm (1). The expected value of rainfall ' $\mathrm{X}$ ' can be obtained using equation 1-3;

$$
\begin{aligned}
& p(x)=\frac{1}{\alpha \times \Gamma(\beta)}\left(\frac{\ln x-y}{\alpha}\right)^{(\beta-1)} e^{-\left(\frac{\ln x-y}{\alpha}\right)} \\
& \ln X_{T}=\ln X_{\text {ave }}-K \sigma
\end{aligned}
$$

where, $X_{\text {ave }}$ is the mean of logarithmic values of observed rainfall and $\sigma$ is the standard deviation of these values. Frequency factor $K_{T}$ is taken from Benson corresponding to coefficient of skewness $\left(C_{s}\right)$ of transformed variate as

$$
K \approx z+\left(z^{2}-1\right) \frac{C s}{6}+\frac{1}{3}\left(z^{3}-6 z\right)\left(\frac{C s}{6}\right)^{2}-\left(z^{2}-1\right)\left(\frac{C s}{6}\right)^{3}+z\left(\frac{C s}{6}\right)^{4}+\frac{1}{3}\left(\frac{C s}{6}\right)^{5}
$$

While for Gumbel distribution, the expected rainfall ' $\mathrm{X}$ ' is computed by equation 4

$$
X_{T}=X_{\text {ave }}-K_{T} \sigma
$$

Where, $K_{\mathrm{T}}$ is frequency factor which is calculated by the formula given by Gumbel as

$$
y=-\ln \left[-\ln \left(1-\frac{1}{T_{r}}\right)\right]
$$

Return period, Tr is defined as the average number of years between occurrences of a hydrologic event with a specified magnitude or greater. The probability that a rainfall event with specified 
duration and depth will be equalled or not exceeded in any one year called non exceedance probability p'. This probability is equal to the inverse of the return period $\mathrm{Tr}$, that is:

$$
\mathrm{p}^{\prime}=\frac{1}{\operatorname{Tr}}, \quad \text { for } \operatorname{Tr}>1
$$

The best fit distribution was decided by using chi-square test for goodness of fit. The chi-square test can be calculated using equation 8 .

$$
\chi 2=\sum_{\mathrm{i}=1}^{\mathrm{k}} \frac{(O i-E i)}{E i}
$$

Where, $\mathrm{O}_{i}$ is the observed rainfall and $\mathrm{Ei}$ is the expected rainfall and will have chi-square distribution with $(\mathrm{N}-\mathrm{k}-1)$ degree of freedom (df). The best probability distribution function was determined by comparing Chi square values obtained from each distribution and selecting the function that gives smallest chi-square value [1]. If $x^{2}$ calculated $>x^{2}$ table then the difference between observed and expected values is considered to be significant.

\begin{tabular}{|c|c|c|c|c|c|}
\hline Location & Latitude & Longitude & $\begin{array}{l}\text { Standard } \\
\text { deviation }\end{array}$ & Minimum & Maximum \\
\hline $\begin{array}{l}\text { DID Store } \\
\text { Teluk Intan }\end{array}$ & 040100 & 1010210 & 25.219 & 61 & 138 \\
\hline $\begin{array}{l}\text { Stage I } \\
\text { Sungai Manik }\end{array}$ & 040330 & 1010440 & 22.110 & 65 & 153.5 \\
\hline $\begin{array}{l}\text { DID Sungai } \\
\text { Mengkuang }\end{array}$ & 040020 & 1010810 & 18.074 & 77 & 141.5 \\
\hline $\begin{array}{l}\text { Stage IV } \\
\text { Sungai Manik }\end{array}$ & 040635 & 1010135 & 37.814 & 64.5 & 223.5 \\
\hline $\begin{array}{l}\text { DID House } \\
\text { Labu Kubong }\end{array}$ & 040805 & 1010555 & 29.061 & 60 & 162 \\
\hline
\end{tabular}

Table 1: Locations and some summary statistics for five rainfall stations

\section{Results and Discussions}

Maximum daily rainfall corresponding date for the period of 10 years (1984 to 1993) is presented by month in Table 2 . The monthly minimum and maximum for one day maximum rainfall and the average of these 12 month rainfall for the overall five rainfall stations was also shown in Table 2. It observed that Pt. IV Sg. Manik has the highest average value that is $118.792 \mathrm{~mm}$.

Table 2: Maximum daily rainfall for January to December (1984 to 1993)

\begin{tabular}{cccccc}
\hline Month/Station & Telok Intan & $\begin{array}{c}\text { Pt. 1 Sg. } \\
\text { Manik }\end{array}$ & Sg. Mengkuang & $\begin{array}{c}\text { Pt. Iv Sg. } \\
\text { Manik }\end{array}$ & $\begin{array}{c}\text { Labu } \\
\text { Kubong }\end{array}$ \\
\hline Jan & 77.0 & 72.5 & 82.5 & 83.5 & 72.0 \\
Feb & 113.5 & 85.0 & 113.5 & 223.5 & 162.0 \\
March & 84.5 & 83.5 & 141.5 & 120.5 & 121.0 \\
Apr & 84.0 & 100.0 & 105.0 & 115.0 & 105.5 \\
May & 65.5 & 92.0 & 98.5 & 120.0 & 74.0 \\
June & 116.5 & 79.5 & 113.5 & 120.0 & 105.5 \\
July & 100.0 & 65.0 & 104.0 & 105.5 & 60.0 \\
Aug & 118.5 & 83.5 & 77.0 & 64.5 & 64.0 \\
Sept & 63.0 & 81.5 & 99.0 & 107.5 & 94.0 \\
Oct & 61.0 & 85.0 & 132.5 & 110.0 & 94.5 \\
Nov & 138.0 & 153.5 & 103.5 & 130.0 & 85.0 \\
Dec & 108.0 & 89.5 & 103.0 & 125.5 & 121.0 \\
\hline Ave & $\mathbf{9 4 . 1 2 5 0}$ & $\mathbf{8 9 . 2 0 8}$ & $\mathbf{1 0 6 . 1 2 5}$ & $\mathbf{1 1 8 . 7 9 2}$ & $\mathbf{9 6 . 5 4 2}$ \\
\% Above Ave & $\mathbf{5 0 . 0 0}$ & $\mathbf{3 3 . 3 3}$ & $\mathbf{3 3 . 3 3}$ & $\mathbf{5 0 . 0 0}$ & $\mathbf{4 1 . 6 7}$ \\
Min & $\mathbf{6 1 . 0}$ & $\mathbf{6 5 . 0}$ & $\mathbf{7 7 . 0}$ & $\mathbf{6 4 . 5}$ & $\mathbf{6 0 . 0}$ \\
Max & $\mathbf{1 3 8 . 0}$ & $\mathbf{1 5 3 . 5}$ & $\mathbf{1 4 1 . 5}$ & $\mathbf{2 2 3 . 5}$ & $\mathbf{1 6 2 . 0}$ \\
\hline
\end{tabular}




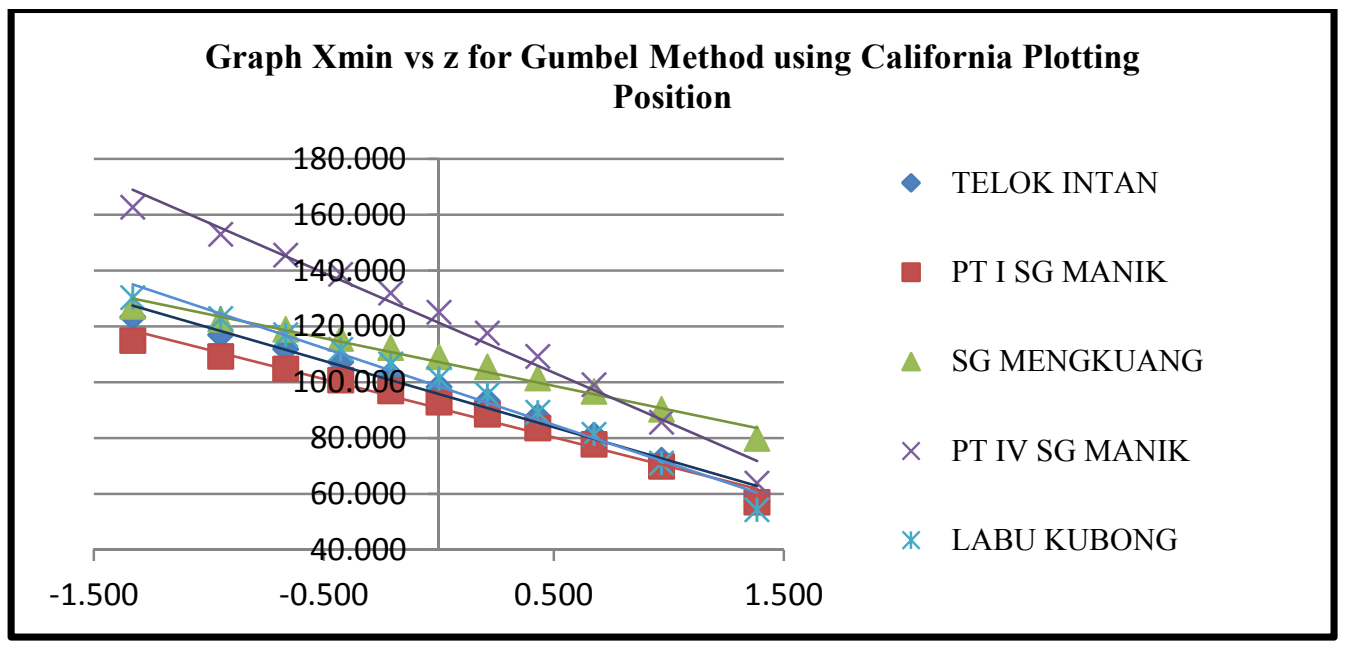

Fig 1: Graph Xmin versus z for Gumbel Method using California Plotting Position

The rainfall analysis using different probability distributions such as log-Pearson type-III and Gumbel using California's method were calculated. Figure 1 shows the the Gumbel method is suitable to use for all the stations based on the scatter plot that close to the straight line. Refer to Table 3, both probability distribution functions were compared by chi square test of goodness of fit and then selecting the function that gave the smallest chi-square value determined the best probability distribution function. The result shows that both distributions can be used for rainfall station at Sg. Mengkuang and Labu Kubong, meanwhile only Gumble distribution is suitable to use for Telok Intan's rainfall station. For Pt. 1 and Pt. IV Sg. Manik's rainfall stations, both distributions are not suitable to be used. Table 4 shows the correlation between rainfall and temperature at five stations at Teluk Intan. Based on the results, rainfall and temperature seems not correlated at all based on the negative value for every five rainfall station.

Table 3: Chi-square value for Gumble and Log-Pearson III distribution for five rainfall stations at Teluk Intan

\begin{tabular}{|c|c|c|c|c|}
\hline \multirow{2}{*}{ Station } & \multicolumn{4}{|c|}{ Chi Square $\chi^{2}$} \\
\hline & Distribution & From Calculation & From Table & Result \\
\hline \multirow{2}{*}{ Telok Intan } & Gumble & 9.5869 & 12.59 & $\sqrt{ }$ \\
\hline & Log Pearson III & 15.1120 & 14.07 & $\mathbf{X}$ \\
\hline \multirow{2}{*}{ Pt. 1 Sg. Manik } & Gumble & 45.6379 & 15.51 & $\mathbf{X}$ \\
\hline & Log Pearson III & 27.4922 & 15.51 & $\mathbf{X}$ \\
\hline \multirow[b]{2}{*}{ Sg. Mengkuang } & Gumble & 4.9239 & 12.59 & $\sqrt{ }$ \\
\hline & Log Pearson III & 1.6015 & 11.07 & $\sqrt{ }$ \\
\hline \multirow{2}{*}{ Pt. IV Sg. Manik } & Gumble & 52.8443 & 25.00 & $\mathbf{X}$ \\
\hline & Log Pearson III & 25.9532 & 21.03 & $\mathbf{X}$ \\
\hline \multirow{2}{*}{ Labu Kubong } & Gumble & 12.0298 & 16.92 & $\sqrt{ }$ \\
\hline & Log Pearson III & 5.1978 & 16.92 & $\sqrt{ }$ \\
\hline
\end{tabular}

Table 4: Correlation between rainfall and temperature for five stations

\begin{tabular}{lc}
\hline \multicolumn{1}{c}{ Station } & Correlation \\
\hline Teluk Intan & 0.17 \\
Pt. 1 Sg. Manik & 0.28 \\
Sg. Mengkuang & 0.17 \\
Pt. Iv Sg. Manik & 0.40 \\
Labu Kubong & 0.07 \\
\hline
\end{tabular}

\section{Conclusion}

This study is to analyze the monthly rainfall pattern from 1984 to 1993 for the Teluk Intan Basin. Pt. IV Sg Manik in February received the highest amount of one day maximum rainfall (27\%) 
followed by Labu Kubong in also February (20\%) and Pt. I Sg. Manik in November (19\%). The frequency analysis of daily maximum rainfall or identifying the best fit probability distribution can be studied for four probability distributions such as log-Pearson type III and Gumbel by using Chisquare goodness of fit test. It was observed that both probability distribution functions fitted significantly for Sg. Mengkuang and Labu Kubong, Gumbel distribution fitted significantly for Telok Intan. Moreover, both probability distribution functions not fitted for Pt. I Sg. Manik and Pt. IV Sg Manik. Furthermore, rainfall and temperature seems not correlated at all based on the negative value for every five rainfall station.

\section{References}

[1] Agarwal, M. C., V. S. Katiyar and Ram Babu (1988). Probability analysis of annual maximum daily rainfall of U. P., Himalaya. Indian Journal of Soil Conservation, 16(1) : 35-42.

[2] Aronica G, Cannarozzo M and Noto L 2002 Investigating the changes in extreme rainfall series recorded in an urbanised area; Water Science and Technology 45 49-54.

[3] Cannarozzo M, Dasaro F and Ferro V 1995 Regional rainfall and flood frequency-analysis for Sicily using the 2component extreme-value distribution; Hydrol. Sci. J. 40 19-42.

[4] Crisci A, Gozzini B, Meneguzzo F, Pagliara S and Maracchi G 2002 Extreme rainfall in a changing climate: regional analysis and hydrological implications in Tuscany; Hydrol. Processes 16 1261-1274.

[5] Elnaqa A and Abuzeid N 1993 A program of frequency analysis using Gumbel's method; Ground Water 31 1021-1024.

[6] Farago T and Katz R 1990 Extremes and design values in climatology; World Meteorological Organization WCAP14, WMO/TD-No. 386.

[7] Ferro V 1993 Rainfall intensity-duration-frequency formula for India - discussion; Journal of Hydraulic Engineering-ASCE 119 960-962.

[8] IPCC TAR WG2 (2001), McCarthy, J. J.; Canziani, O. F.; Leary, N. A.; Dokken, D. J.; and White, K. S., ed., Climate Change 2001: Impacts, Adaptation and Vulnerability, Contribution of Working Group II to the Third Assessment Report of the Intergovernmental Panel on Climate Change, Cambridge University Press, ISBN 0-521-80768-9 (pb: 0-521-01500-6).

[9] Koutsoyiannis D and Baloutsos G 2000 Analysis of a long record of annual maximum rainfall in Athens, Greece, and design rainfall inferences; Natural Hazards 22 29-48.

[10]Le Treut, H., Somerville, R., Cubasch, U., Ding, Y., Mauritzen, C., Mokssit, A ., ...\& Prather, M. (2007). Historical overview of climate change. In S. Solomon, D. Qin, M. Manning, Z. Chen, M. Marquis, K.B. Averyt, M. Tignor and H.L.Miller (Eds). Climate Change 2007: The Physical Science Basis, pp 93-127.

[11] Miroslava U 1991 The extreme value distribution of 5-min rainfall data Belgrade; Theoretical and Applied Climatology 44 223-228.

[12] Nguyen V T V, Nguyen T D and Wang H 1998 Regional estimation of short duration rainfall extremes; Water Science and Technology 37 15-19.

[13] Parida B P 1999 Modelling of Indian summer monsoon rainfall using a four-parameter Kappa distribution; Int. J. Climatol. 19 1389-1398.

[14] Withers C S and Nadarajah S 2000 Evidence of trend in return levels for daily rainfall in New Zealand; J. Hydrol. (NZ) 39 155-166.

[15]Zalina M D, Desa M N M, Nguyen V T V and Kassim A H M 2002 Selecting a probability distribution for extreme rainfall series in Malaysia; Water Science and Technology 45 63-68. 